\title{
Pengaruh Pemilihan Kala Ulang Debit Banjir Rancangan Metode HSS Nakayasu Terhadap Dimensi Sand Pocket di Gunung Merapi
}

\author{
Imam Sudrajad ${ }^{1 *}$, Yeri Sutopo ${ }^{2}$, dan Agung Sutarto ${ }^{3}$ \\ 1,2,3 Jurusan Teknik Sipil,Fakultas Teknik, Universitas Negeri Semarang-Semarang \\ *e-mail corresponding author : imamsudrajad@students.unnes.ac.id
}

\begin{abstract}
ABSTRAK
Debit banjir rancangan menjadi parameter penting dalam perencanaan desain bangunan air. Saat analisis debit banjir rancangan, pemilihan kala ulang menjadi hal yang krusial karena akan menentukan besarnya debit banjir rancangan. Pemilihan kala ulang disesuaikan dengan karakteristik Daerah Aliran Sungai (DAS). Lokasi perencanaan Sand Pocket berada di kali Woro, Klaten, Jawa Tengah. Tidak tersedianya data debit banjir rancangan pada lokasi pengamatan mengakibatkan analisis debit banjir rancangan ini dilakukan. Penelitian ini berfokus untuk membandingkan besaran debit banjir rancangan dari kala ulang yang berbeda yaitu Q5th, Q10th, Q25th, Q50th, dan Q100th. Setelah debit banjir didapatkan kemudian digunakan untuk menghitung dimensi bangunan Sand Pocket. Setiap kala ulang yang digunakan pada penelitian ini menghasilkan dimensi bangunan yang berbeda di beberapa bagian. Analisis ini memperlihatkan bagian dimensi bangunan yang berbeda akibat perbedaan debit banjir yang dihasilkan yaitu pada bagian Main Dam dan Sub Dam adalah tinggi efektif, kemiringan hulu (m), tinggi aliran di atas mercu, tinggi jagaan, kedalaman pondasi, dan lebar dasar. Pada bagian Kolam olak mendapat perbedaan dimensi panjang lantai dan tebal lantai kolam. Kemudian perbedaan dimensi pula di kemiringan sisi hulu sayap Main Dam dan Sub Dam. Pemilihan kala ulang ini menentukan besaran debit banjir rencana yang akan dihasilkan yang berpengaruh terhadap dimensi Sand Pocket yang akan direncakanan.
\end{abstract}

Kata kunci : debit banjir; kala ulang; nakayasu; sand pocket.

\section{ABSTRACT}

Design flood discharge has become an important parameter in hydraulic construction design planning. When analyzing it, return period selection is crucial because it will determine the amount of design flood discharge. The return period selection is adjusted to the characteristics of the Watershed (DAS). The Sand Pocket planning location is in Woro River, Klaten, Central Java. The unavailability of design flood discharge data at the observation site resulted in the design flood discharge analysis being carried out. This study focuses on comparing the magnitude of design flood discharges from different return periods, namely Q5th, Q10th, Q25th, Q50th, and Q100th. After the flood discharge is obtained, it is utilized to calculate the dimensions of the Sand Pocket construction. Each return period used in this study produced different dimensions of the building in several parts. This analysis shows the different dimensions of the building due to differences in flood discharge generated, namely the Main Dam and Sub Dam parts including effective height, upstream slope (m), flow height above the lighthouse, freeboard, foundation depth, and base. In the part of apron, there are differences of floor length and thickness dimension. The difference dimensions also appeared on the upstream side slope of Main Dam and Sub Dam. This return period selection determines the amount of the design flood discharge that will affect the dimensions of the Sand Pocket that will be planned.

Keywords : flood discharge; return period; nakayasu; sand pocket

Cara Mengutip : Sudrajad, I., Sutopo, Y., Sutarto, A. (2020). Pengaruh Pemilihan Kala Ulang Debit Banjir Rancangan Metode HSS Nakayasu Terhadap Dimensi Sand Pocket di Gunung Merapi. Reka Buana : Jurnal Ilmiah Teknik Sipil dan Teknik Kimia, 5(1), 80-89. http://dx.doi.org/10.33366/rekabuana.v5i1.1680 


\section{PENDAHULUAN}

Tahun 2012 endapan material yang berpotensi menjadi banjir lahar sebesar 7,5 juta m3. Sisa material erupsi gunung Merapi pada tahun 2010 yang mengendap di tujuh sungai berhulu di gunungapi aktif tersebut masih mencapai sekitar 58 juta $\mathrm{m} 3$ dan berpotensi menjadi banjir lahar saat musim hujan. [1]

Dalam merencanakan Sand Pocket langkah pertama yang harus dilakukan adalah merencanakan debit banjir rancangan. Debit banjir rancangan dihitung menggunakan data curah hujan yang didapatkan dari stasiun penakar curah hujan yang berada di sekitar Daerah Aliran Sungai (DAS). Debit banjir rancangan tersebut kemudian digunakan untuk menghitung dimensi bangunan Sand Pocket.

Dam Pengendali Sedimen atau dikenal dengan Dam Sabo merupakan salah satu bangunan pengendali sedimen yang bekerja dalam satu sistem pengendalian gunamenvapaitujuan yang ditetapkan, yaitu mengelola kelebihan sedimen sedemikian rupa sehingga tidak membahayakan bagian hilinnya. Dam Pengendali Sedimen memiliki peran dominan dalam mengelola volume sedimen melalui fungsi mandi yang ada dalam setiap DAM Sabo, yaitu fungsi menampung, mengontrol dan menahan sedimen. Fungsi-fungsi tersebut dalam satu sistem pengendalian sedimen memberikan kontribusi secara koherensif dalam pengelolaan kelebihean sedimen yaitu mereduksi jumlah sedimen, mereduksi proses sedimen dan mengontrol aliran sedimen. [2]

Salah satu bangunan sedimen yang masih sejenis dengan Sabo DAM adalah kantong pasir / Sand Pocket. Sand Pocket dibuat menutup cekungan yang terdapat di ujung atau di pangkal alur sungai dengan konstruksi bendungan dan tanggul keliling untuk menahan/menimbun debris yang memasukinya dan meneruskan aliran air ke hilir melewati suatu mercu limpasan yang disediakan pada bendungannya. Bangunan tersebut dapat dilengkapi jalan akses untuk memfasilitasi penambangan bahan galian $\mathrm{C}$ dari dalamnya. Aktivitas ini akan membantu mengosongkan deposit di dalamnya agar memulihkan volume penampungan rencana untuk mengendalikan sedimentasi aliran sungai serta memberikan penghasilan bagi para penambangnya. [2]

Hidrograf Satuan Sintetik (HSS) Nakayasu merupakan suatu cara yang digunakan untuk mendapatkan hidrograf banjir rencana dalam suatu DAS, dengan mempertimbangkan karakteristik atau parameter daerah aliran sungai tersebut. Metode ini akan digunakan untuk menghitung debit banjir maksimum di DAS sungai woro. HSS Nakayasu dikembangkan berdasarkan beberapa sungai di Jepang. [3]. Hidrograf merupakan penyajian grafis antara salah satu unsur aliran dengan waktu. Hidrograf menjunjukan sifat tanggapan DAS terhadap masukan hujan dengan intesitas, lama dan tagihan tertentu. Penggunaan metode ini memerlukan beberapa karakteristik parameter daerah lainnya, seperti tenggang waktu dari permulaan hujan sampai puncak (time of peak), tenggang waktu dari titik berat hujan sampai titik berat hidrograf (time lag), tenggang waktu hidrograf (time base of bydrograph), luas DAS, panjang alur sungai utama terpanjang (length of the longest channel). [4]

Penjelasan mengenai karakteristik bentuk hidrograf yang merupakan dasar dari konsep hidrograf satuan menurut Triatmodjo, (2008) [5] dapat dilihat pada gambar dibawah ini: 

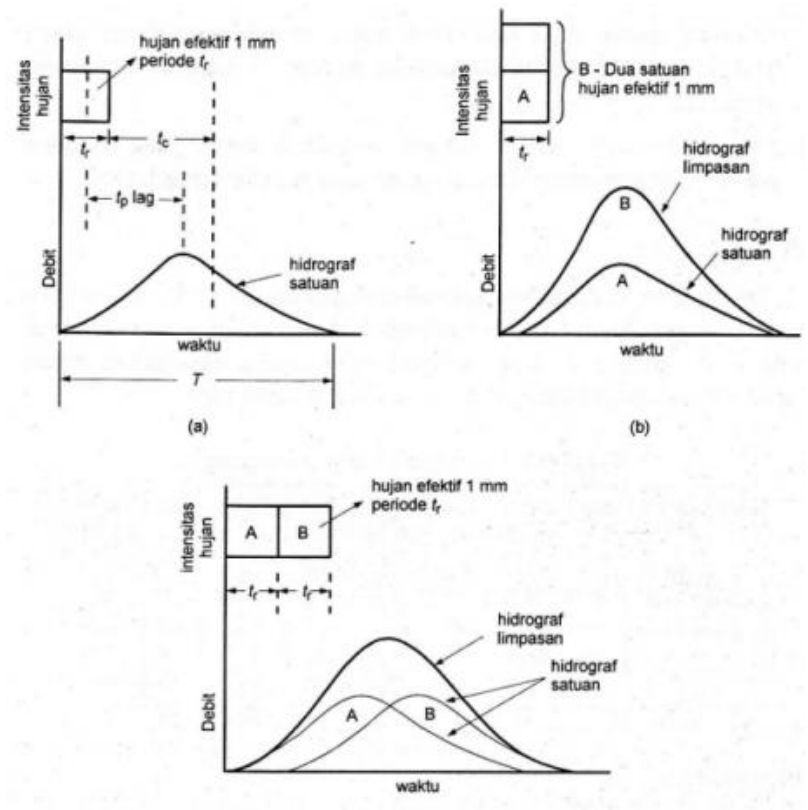

(c)

\section{Gambar 1. Prinsip hidrograf satuan Triatmodjo, B (2008)}

Kegunaan hidrograf satuan sendiri untuk memperkirakan debit banjir rencana pada suatu DAS atau sub-DAS. Menurunkan hidrograf satuan DAS atau sub-DAS lain khususnya yang mempunyai kemiripan karakter, penggunaannya harus memperhatikan luas DAS atau sub-DAS. Penggunaan hidrograf satuan tidak boleh lebih dari $5000 \mathrm{~km}^{2}$, kecuali diperkenankan menggunakan akurasi. [6].

Berdasarkan permasalahan yang ada dapat dirumuskan tujuan yang akan dicapai yaitu: (a) Menganalisis luas Daerah Aliran Sungai (DAS) dari titik lokasi rencana Sand Pocket; (b) Menganalisis nilai debit banjir kala ulang 5th, 10th, 25th, 50th dan 100th dengan metode Hidrograf Satuan Sintetik Nakayasu; (c) Menganalisis dimensi bangunan Sand Pocket yang sesuai dengan debit banjir yang didapatkan dari kala ulang kala ulang 5th, 10th, 25th, 50th dan 100th.

\section{METODE PENELITIAN}

Dalam penelitian yang dilakukan di kali Woro data yang digunakan adalah data primer dan data sekunder. Data primer diperoleh dari survei dan pengujian material secara langsung sedangkan data sekunder diperoleh dari lembaga penyedia data yang dibutuhkan tersebut. Data primer yang didapatkan di lapangan berupa dimensi penampang kali Woro, sampel tanah yang selanjutnya akan diuji di Laboratorium Mekanika Tanah dan kondisi sungai serta area sekitarnya. Sedangkan untuk data sekunder yang digunakan adalah data curah hujan tahunan yang dimana lokasi stasiun hujan berada didekat kali Woro atau mempunyai elevasi lebih tinggi dari lokasi rencana Sand Pocket. Selanjutnya peta topografi yang didapatkan dari lembaga penyedia peta kemudian diolah untuk mendapatkan besaran luas DAS serta panjang kali Woro sesuai titik koordinat rencana Sand Pocket.

Pada penelitian yang dilakukan oleh penulis sebelumnya yang dimuat dalam skripsi dengan judul Dimensi dan Stabilitas Sand Pocket di kali Woro, Koordinat 7044'42.3"LS 110³1'53.9"BT Klaten, Jawa Tengah. Skripsi tersebut membahas tentang perencanaan dimensi dan stabilitas Sand Pocket di kali Woro. Perhitungan dimensi pada skripsi tersebut menggunakan debit banjir rencana dari kala ulang 50 tahun. Sedangkan stabilitas yang dihitung berdasarkan pada kondisi aliran air normal, aliran air banjir dan gempa.

Proses analisis perhitungan dimensi Sand Pocket dapat dilihat di gambar 2 . 


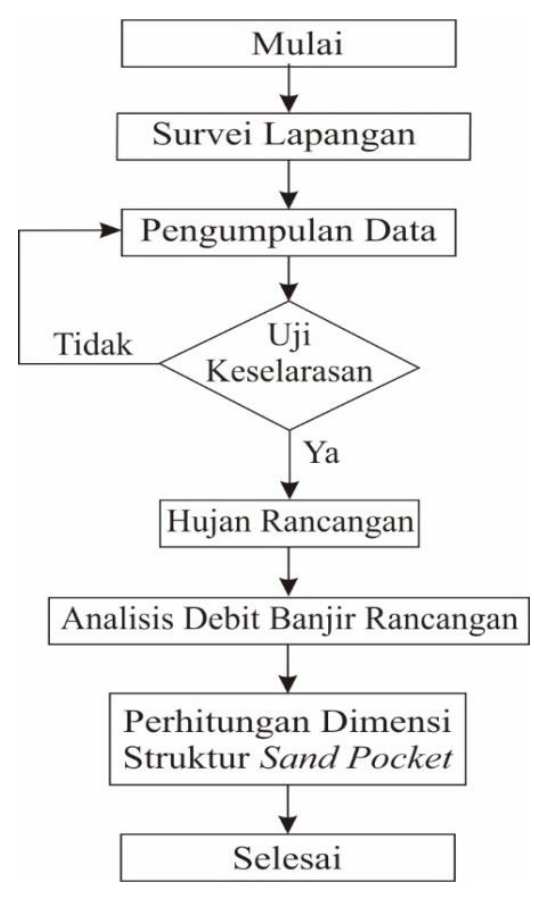

Gambar 2. Bagan alir penelitian

Peta DAS digunakan untuk membagi daerah cakupan stasiun hujan yang mewakili luasan daerah hujan dari suatu stasiun penakar curah hujan. Untuk penelitian ini, penulis menggunakan teknik Polygon Thisessen karena lebih efektif dari segi waktu penlitian dan ketelitiannya. Karena teknik Polygon Thiessen menghasilkan angka curah hujan yang lebih akurat dibanding rata rata aritmatik dan dari segi waktu lebih membutuhkan sedikit waktu daripadi cara isohyet. Teknik Isobyet yang mana lebih teliti dibanding dua cara diatas. Namun, cara perhitungan ini memerlukan banyak waktu karena garis-garis isohyet yang baru perlu ditentukan untuk setiap curah hujan. [7]

Luas DAS dan panjang sungai yang telah didapatkan digunakan untuk mengolah debit banjir rancangan, dipadukan dengan data curah hujan dari 3 stasiun berbeda. Pengolahan dimulai dari mencari curah hujan maksimum kemudian data tersebut diuji sebaran menggunakan uji Smirnov Kolmogorov. Setalah memenuhi kemudian dilanjutkan dengan perhitungan frekuensi hujan rancangan dan yang terakhir menghitung debit banjir menggukanan metode HSS Nakayasu. Persamaan yang digunakan untuk analisis debit banjir rancangan metode HSS Nakayasu berdasarkan SNI 2415-2016 tentang Tata Cara Perhitungan Debit Banjir Rencana [8] yaitu : $\quad \operatorname{tg}=0,4+0,058 x L$

untuk $\mathrm{L}>15 \mathrm{k}$

$\operatorname{tg}=0,21 x L^{0,7}$ untuk $\mathrm{L}<15 \mathrm{~km}$

$t p=\operatorname{tg}+0,8 \operatorname{Tr}(2.25)$

$T_{0,3}=\alpha \cdot \operatorname{tg}$

$Q_{p}=\frac{1}{3,6} x A x R_{0} x \frac{1}{\left(0,3 x t_{p} x t_{0,3}\right)}$

Keterangan:

tg : waktu kelambatan (jam)

$\mathrm{L} \quad$ : panjang sungai $(\mathrm{Km})$

T0,3 : waktu saat debit sama dengan 0,3 kali debit puncak (jam)

1,5 t0,3 : waktu saat debit sama dengan 0,32 kali debit puncak (jam)

$\alpha \quad$ : koefisien, nilainya antara $1,5-3,0$

$$
\alpha=\frac{0,47(A \cdot L)^{0,25}}{t g} \text {. }
$$

tp : waktu puncak (jam)

Qp : debit puncak (m3/det)

A : luas DPS (Km2)

$\operatorname{Tr} \quad$ : durasi hujan $(j a m)=(0,5 \times \mathrm{tg}) \mathrm{s} / \mathrm{d}(1$ $\mathrm{x}$ tg)

R0 : satuan kedalaman hujan (1 mm).

1) Grafik untuk bagian lengkung naik $(0<\mathrm{t}$ $<\mathrm{tp})$

$$
Q=Q_{p}{\frac{t}{t_{p}}}^{2,4}
$$

2) Grafik untuk bagian lengkung turun

a) Jika tp $<\mathrm{t}<\mathrm{t} 0,3$

$$
Q=Q_{p} x 0,3^{\frac{t-t_{p}}{t_{0,3}}}
$$

b) Jika tp $<$ t $<1,5$ t0,3

$Q=Q_{p} x 0,3^{\frac{t-t_{p}+0,5 x t_{0,3}}{1,5 x t_{0,3}}}$

Jika $\mathrm{t}>1,5 \mathrm{t} 0,3$

$Q=Q_{p} x 0,3^{\frac{t-t_{p}+1,5 x t_{0,3}}{2 x t_{0,3}}}$ 
Debit banjir rancangan tersebut kemudian digunakan untuk menghitung dimensi bangunan Sand Pocket yang sesuai dengan SNI 2815-2015 tentang Desain Bangunan Penahan Sedimen. Bagian bangunan yang dihitung antara lain dimensi Main Dam, Kolam Olak (Apron), Sub Dam dan Dinding Tepi pada bangunan Sand Pocket dengan tinggi dan lebar penampang kali Woro.

Data yang dibutuhkan untuk analisis tersebut yaitu: (1) Peta Daerah Aliran Sungai (DAS) kali Woro dari titik lokasi Sand Pocket.; (2) Data curah hujan 10 tahunan stasiun penakar hujan terdekat dengan lokasi DAS kali woro serta yang mempunyai data terbaru dan lengkap. Stasiun penakar curah hujan yang digunakan antara lain Sta. Deles, Sta. Karangnongko dan Sta. Bronggang.; (3) Data parameter tanah lokasi Sand Pocket.

\section{HASIL DAN PEMBAHASAN}

\subsection{Derah Aliran Sungai (DAS) Kali Woro}

Lokasi penelitian ini berada di kali Woro Kabupaten Klaten, Jawa Tengah. Kondisi dari hulu hingga hilir sungai seluruhnya berada di kabupaten Klaten. Bagian hilir sungai ini tidak langsung tembus ke Samudra Hindia, namun bertemu dengan sungai lainnya dan selanjutnya menuju ke laut. Sungai ini memiliki kemiringan ratarata $1 / 35 \mathrm{~s} / \mathrm{d} 1 / 4$ dari hulu sampai hilir dan lebar $10 \mathrm{~m} \mathrm{~s} / \mathrm{d} 500 \mathrm{~m}$. [9]

Menggunakan aplikasi ArcGis 10.6 peta DAS kali Woro diolah untuk mendapatkan data pendukung dalam analisis yang akan dikerjakan pada proses selanjutnya. Panjang sungai dari hulu hingga titik lokasi penelitian adalah $37,55 \mathrm{~km}$ dan luas DAS kali sebesar 20,7495 $\mathrm{km}^{2}$. Setelah mendapatkan data tersebut maka dilanjutkan dengan membagi luasan DAS menjadi 3 bagian tangkapan stasiun hujan.

\subsection{Perhitungan Debit Banjir Rancangan}

Dalam penelitian ini menggukan 3 stasiun hujan yang terdekat dengan sungai untuk analisis hidrologi yang akan dilakukan. Setelah menentukan lokasi stasiun hujan yang dipilih. Kemudian dibuatlah Polygon Thiessen untuk membagi luas wilayah cakupan pada masing - masing stasiun hujan menggunakan aplikasi ArcGis 10.6 dengan hasil sebagai berikut :

Tabel 1. Pembagian luasan daerah cakupan stasiun hujan dengan metode Polygon Thiessen

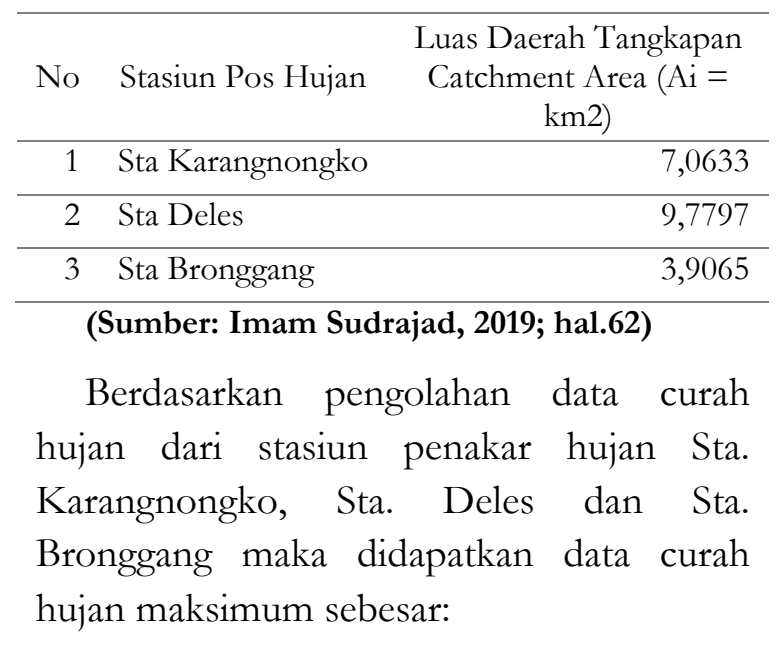

Tabel 2. Curah hujan maksimum tahunan

\begin{tabular}{ccc}
\hline No & Tahun & Curah Hujan (mm) \\
\hline $\mathbf{1}$ & 2009 & 110,71 \\
\hline $\mathbf{2}$ & 2010 & 94,99 \\
\hline $\mathbf{3}$ & 2011 & 82,51 \\
\hline $\mathbf{4}$ & 2012 & 89,55 \\
\hline $\mathbf{5}$ & 2013 & 86,12 \\
\hline $\mathbf{6}$ & 2014 & 80,27 \\
\hline $\mathbf{7}$ & 2015 & 91,50 \\
\hline $\mathbf{8}$ & 2016 & 105,74 \\
\hline $\mathbf{9}$ & 2017 & 107,03 \\
\hline $\mathbf{1 0}$ & 2018 & 97,06 \\
\hline
\end{tabular}

(Sumber: Imam Sudrajad, 2019; hal.65) 
Data curah hujan tersebut kemudian diolah menggunakan metode Polygon Thiessen untuk mendapatkan data hujan jam jaman yang nantinya digunakan untuk menghitung debit banjir rancangan dengan kala ulang 50 tahunan (Q50) menggunakan metode HSS Nakayasu. Perhitungan tersebut menghasilkan debit banjir rancangan dengan kala ulang 50 tahunan (Q50) sebesar $123,4 \mathrm{~m} 3 / \mathrm{s}$. Grafik hidrograf yang dihasilkan dari perhitungan kala ulang 50 tahunan adalah :

\section{Grafik Hidrograf Kala Ulang 50 th}

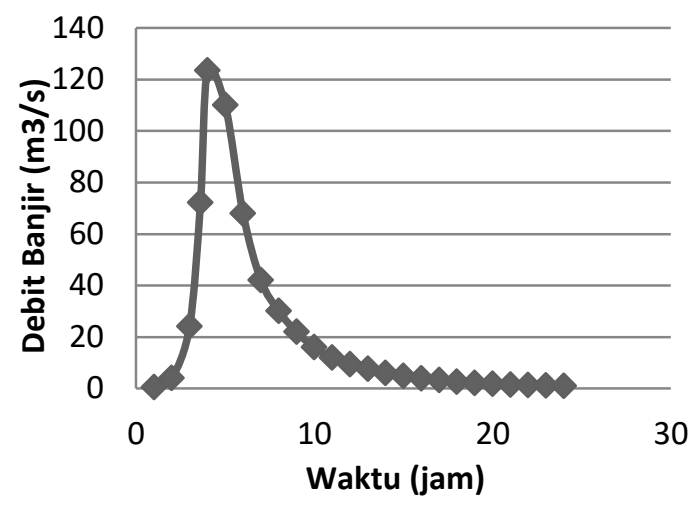

Gambar 3. Grafik Hidrograf kala ulang 50 tahun (Sumber: Sudrajad, 2020; hal.73)

Hasil dari perhitungan debit banjir rancangan dengan kala ulang 5 tahun, 10, tahun, 25 tahun, 50 tahun, dan 100 tahun dapat dilihat di grafik berikut :

\section{Grafik Debit Banjir Rancangan}

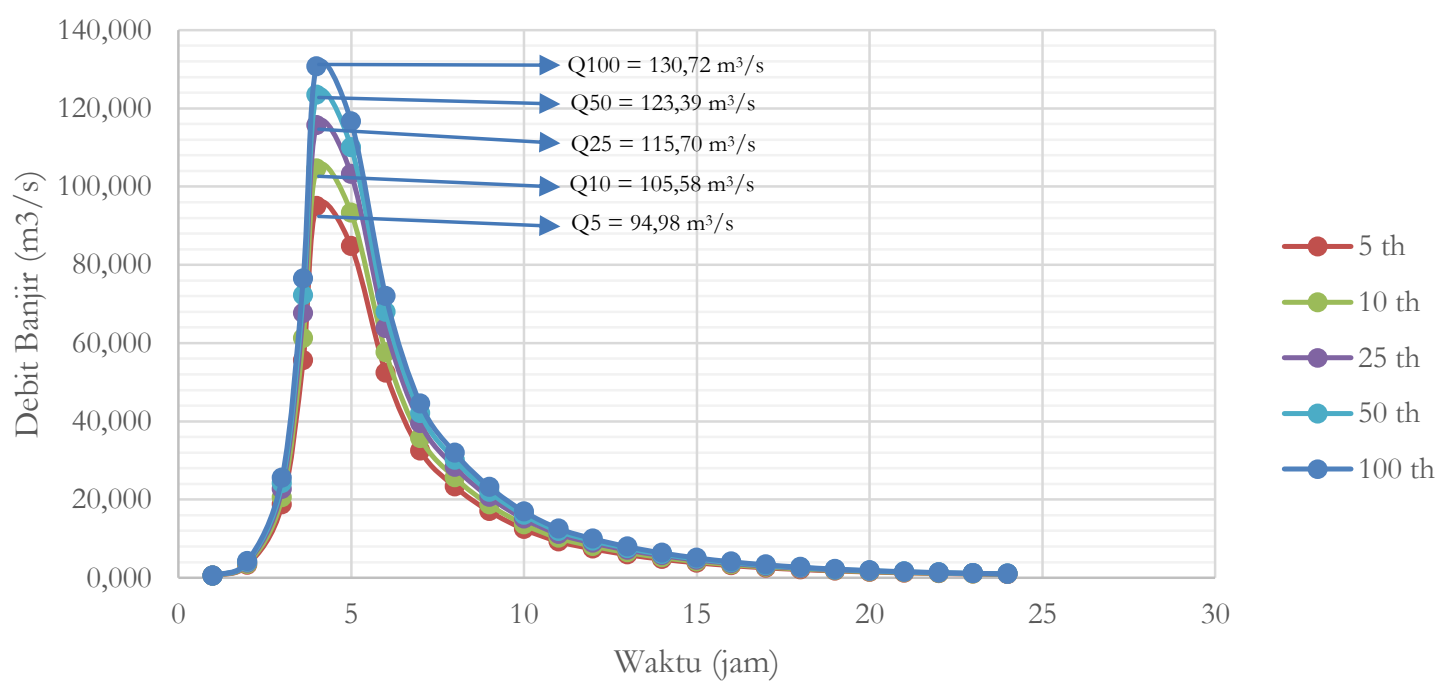

Gambar 4. Grafik debit banjir rancangan tiap kala ulang

\section{Perencanaan Dimensi Sand Pocket}

Dalam perencanaan perhitungan dimensi Sand Pocket ini menggunakan panduan dari SNI 2815-2015 dan Pd T-12-2004-A. Data debit banjir yang digunakan yaitu hasil dari perhitungan menggunakan kala ulang 50 tahun. Berikut ini merupakan perhitungan dimensi Sand Pocket.

\section{Main Dam}

a. Tinggi Main Dam direncanakan 3,5 m (Pd T-12-2004-A)

b. Tinggi air di atas peluap : 
$Q d=\frac{2}{15} C \sqrt{2 g}\left[3 B_{1}+2 B_{2}\right] h_{3}{ }^{3 / 2}$

mendapatkan tinggi 1,753 m.

c. Tinggi jagaan dari Qdesain sebesar 126,158 didapatkan nilai $(F)=1 \mathrm{~m}$.

d. Lebar mercu peluap yang disaran untuk jenis tanah pasir dengan lanai adalah $1,5 \mathrm{~m}-2 \mathrm{~m}$ maka diambil lebar mercu 1,5 m.

e. Kemiringan tubuh bendung dibagi menjadi dua yaitu sisi hulu (m) dan hilir (n) dengan asumsi nilai $\mathrm{n}$ adalah 0,2 maka menggunakan persamaan :

$(1+\alpha) m^{2}+[2(n+\beta)+n(4 \alpha+\gamma)+$ $2 \alpha \beta] m-(1+3 \alpha)+\alpha \beta(4 n+\beta)+$ $\gamma\left(3 n \beta+\beta^{2}+n^{2}\right)=0$

didapatkan nilai $\mathrm{m}$ sebesar 0,5 .

f. Lebar dasar peluap berdasarkan data yang ada sebesar 3,95 m.

\section{Sayap Bendung}

a. Kemiringan terhadap bendung (m2) sebesar 0,5 atau $1: 2$

b. Lebar sayap bagian atas menyesuaikan lebar mercu peluap bendung utama yaitu $1,5 \mathrm{~m}$.

c. Sisi hulu sayap harus tegak.

d. Sisi hilir sayap menyesuaikan kemiringan sisi hilir Main Dam yaitu 0,2 .

Dan untuk panjang sayap masing masing sisi adalah $2,5 \mathrm{~m}$

\section{Kolam Olak (Apron)}

Panjang kolam olak menggunakan persamaan:

$L=l w+x+b_{1}$

didapatkan nilai sebesar $27 \mathrm{~m}$ dan tebal lantai tersejun $0,60 \mathrm{~m}$.

\section{Sub Dam}

Kemiringan hulu dan hili juga sama dengan Main Dam yaitu hulu (m) $=0,5$ dan hilir (n) $=0,2$.

Menggunakan rumus empiris:

$h 2 / h_{1}=\left[\frac{\left\{\left(1+2{F_{r 1}}^{2}\right) x\left(1+82{F_{r 1}}^{2}\right)^{0,5}-5{F_{r 1}}^{2}\right\}}{\left\{\left(1+4 F_{r 1}{ }^{2}\right)-\left(1+8 F_{r 1}{ }^{2}\right)\right\}}-\right.$
$\left.3 / 2{F_{r 1}}^{2 / 3}\right] \ldots \ldots \ldots \ldots \ldots \ldots \ldots \ldots \ldots \ldots \ldots \ldots \ldots \ldots \ldots \ldots \ldots \ldots \ldots \ldots$

tinggi Sub-Dam direncanakan 1,2 m.

\section{Pondasi}

Dengan menggunakan rumus empiris:

$H=\frac{1}{3} s / d \frac{1}{4}\left(h+h_{3}\right)$

didapatkan nilai kedalama pondasi 1,313 s/d 1,751 maka dipilih kedalaman pondasi sebesar $1.75 \mathrm{~m}$.

\section{Lubang Drainase}

Menggunakan persamaan

$Q=2 C d \cdot A \cdot{\sqrt{2 g \cdot h_{o}}}^{0,5}$

untuk mencari luas maksimal lubang drainase dan $A=p . l . n$ untuk mencari jumlah maksimal lubang drainase. Maka jumlah maksimal lubang yang dibutuhkan adalah 24 buah.

\section{Volum Tampungan}

Dengan persamaan:

$V S=\frac{1}{2} \frac{B h_{e}{ }^{2}}{I o-I S}$

dan $I S=\left(\frac{Q d \cdot n_{s}}{(B 1+h 3) h 3^{5 / 3}}\right)^{2}$

maka volume tampungan Sand Pocket sebesar 5962,18 m3.

Hasil dari perhitungan untuk masingmasing kala ulang dapat dilihat di tabel di bawah ini : 
Tabel 4. Perbandingan dimensi Sand Pocket pada debit banjir rancangan kala ulang $5^{\text {th }}$, $10^{\text {th }}, 25^{\text {th }}, 50^{\text {th }}$ dan $100^{\text {th }}$.

HASIL PERHITUNGAN

\begin{tabular}{|c|c|c|c|c|c|c|c|}
\hline \multirow{2}{*}{ Keterangan } & \multirow{2}{*}{ Simbol } & \multicolumn{5}{|c|}{ KALA ULANG } & \multirow{2}{*}{ Satuan } \\
\hline & & 5 th & 10th & 25 th & 50th & 100th & \\
\hline \multicolumn{8}{|l|}{ MAIN DAM } \\
\hline Tinggi total & $\mathrm{H}$ & 3,50 & 3,50 & 3,50 & 3,50 & 3,50 & $\mathrm{~m}$ \\
\hline Tinggi efektif & he & 2,97 & 2,95 & 2,92 & 2,90 & 2,88 & $\mathrm{~m}$ \\
\hline kemiringan sisi hulu & $\mathrm{m}$ & 0,43 & 0,46 & 0,47 & 0,48 & 0,49 & \\
\hline Kemiringan sisi hilir & $\mathrm{n}$ & 0,20 & 0,20 & 0,20 & 0,20 & 0,20 & \\
\hline Lebar mercu & $\mathrm{b}$ & 1,50 & 1,50 & 1,50 & 1,50 & 1,50 & $\mathrm{~m}$ \\
\hline Tinggi aliran diatas mercu & hs/h3 & 1,48 & 1,57 & 1,68 & 1,75 & 1,82 & $\mathrm{~m}$ \\
\hline Tinggi jagaan & $\mathrm{F}$ & 0,80 & 1,00 & 1,00 & 1,00 & 1,00 & $\mathrm{~m}$ \\
\hline Pondasi & $\mathrm{d}$ & 1,35 & 1,37 & 1,40 & 1,42 & 1,44 & $\mathrm{~m}$ \\
\hline Lebar dasar main dam & $\mathrm{b} 2^{\prime}$ & 3,71 & 3,81 & 3,85 & 3,86 & 3,92 & $\mathrm{~m}$ \\
\hline
\end{tabular}

\begin{tabular}{|c|c|c|c|c|c|c|c|}
\hline \multicolumn{8}{|l|}{ Kolam Olak } \\
\hline Panjang lantai kolam olak & $\mathrm{L}$ & 23,73 & 24,59 & 25,53 & 26,15 & 26,72 & $\mathrm{~m}$ \\
\hline tebal lantai kolam olak & $\mathrm{t}$ & 0,53 & 0,55 & 0,58 & 0,60 & 0,62 & $\mathrm{~m}$ \\
\hline
\end{tabular}

\begin{tabular}{llllllll}
\hline SUB DAM & & & & & & & \\
\hline Tinggi total & $\mathrm{H} 2$ & 1,01 & 1,05 & 1,09 & 1,12 & 1,14 & $\mathrm{~m}$ \\
\hline kemiringan sisi hulu (m) & $\mathrm{m} 2$ & 0,43 & 0,46 & 0,47 & 0,48 & 0,49 & \\
\hline Kemiringan sisi hilir (n) & $\mathrm{n} 2$ & 0,20 & 0,20 & 0,20 & 0,20 & 0,20 & \\
\hline Lebar mercu & $\mathrm{b} 2$ & 1,50 & 1,50 & 1,50 & 1,50 & 1,50 & $\mathrm{~m}$ \\
\hline Pondasi & $\mathrm{d} 2$ & 1,35 & 1,37 & 1,40 & 1,42 & 1,44 & $\mathrm{~m}$ \\
\hline
\end{tabular}

\begin{tabular}{lllllll}
\hline Sayap & & & & & & \\
\hline Kemiringan sayap & 0,50 & 0,50 & 0,50 & 0,50 & 0,50 & \\
\hline Kemiringan sisi hulu & 0,43 & 0,46 & 0,47 & 0,48 & 0,49 & \\
\hline Kemiringan sisi hilir & 0,20 & 0,20 & 0,20 & 0,20 & 0,20 & \\
\hline Lebar sayap & 1,50 & 1,50 & 1,50 & 1,50 & 1,50 & $\mathrm{~m}$ \\
\hline Panjang masing-masing sayap & 2,00 & 2,00 & 2,00 & 2,00 & 2,00 & $\mathrm{~m}$ \\
\hline
\end{tabular}

Dari hasil perhitungan diatas tinggi efektif pada Main Dam semakin kecil ketika kala ulang bertambah. Hal ini terjadi karena tebal lantai pada kolam olak (Apron) semakin bertambah disebabkan oleh debit banjir rencana yang juga bertambah besar sehingga tinggi efektif pada Main Dam pun mengecil. Hasil dari desain Sand Pocket yang didapatkan menggunakan kala ulang 50 tahun adalah sebagai berikut :

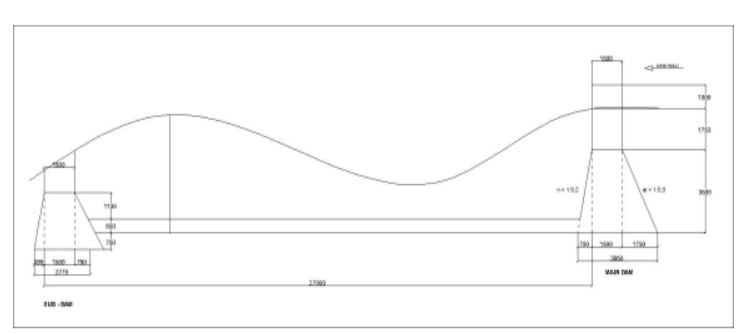

Gambar 5. Desain Sand Pocket dengan kala ulang 50 tahun 


\section{SIMPULAN}

Berdasarkan analisis yang telah dilakukan sesuai dengan metode yang disepakati, maka hasil yang didapatkan yaitu : (1) Luasan luas DAS di kali woro yang didapatkan adalah sebesar 20,75 $\mathrm{km}^{2}$ dengan panjang sungai $37,55 \mathrm{~km}$; (2) Debit banjir yang didaptkan Q5th = $94,98 \mathrm{~m}^{3} / \mathrm{s}$, Q10th $=104,58 \mathrm{~m}^{3} / \mathrm{s}$, Q25th $=115,70 \mathrm{~m}^{3} / \mathrm{s}$, Q50th $=123,39$ $\mathrm{m}^{3} / \mathrm{s}$, Q100th $=130,71 \mathrm{~m}^{3} / \mathrm{s}$.

Perbedaan pemilihan kala ulang dapat mempengaruhi dimensi Sand Pocket. dimensi bangunan yang terpengaruh pada Main Dam dan Sub Dam adalah tinggi efektif, kemiringan hulu (m), tinggi aliran di atas mercu, tinggi jagaan, kedalaman pondasi, dan lebar dasar. Pada bagian Kolam olak mendapat perbedaan dimensi panjang lantai dan tebal lantai kolam. Kemudian perbedaan dimensi pula di kemiringan sisi hulu sayap Main Dam dan Sub Dam. Pemilihan kala ulang ini menentukan besaran debit banjir rencana yang akan dihasilkan yang berpengaruh terhadap dimensi Sand Pocket yang akan direncakanan.

Pemilihan kala ulang ini penting dilakukan berdasarkan jenis bangunan yang akan direncanakan. Perlu meninjau literatur yang sudah mengklasifikasikan jenis bangunan dan kala ulang yang digunakan untuk mendesain bangunan tersebut.

Selain itu dalam merencanakan bangunan Sand Pocket ini perlu dilakukan pengecekan stabilitas sesuai dengan parameter tanah di lapangan pada kondisi yang berbeda-beda sesuai dengan standar yang telah ditentukan.
Analisis yang dilakukan pada penelitian ini mengahasilkan berbagai dimensi Sand Pocket yang berbeda. Sehingga mendapatkan gambaran dimensi yang didapatkan dengan berbagai kala ulang yang digunakan.

\section{UCAPAN TERIMA KASIH}

Terima kasih terhadap Bali Sabo Yogyakarta, BPSDA Yogyakarta dan BPSDA Jawa Tengah yang telah membantu menyediakan data curah hujan dari masing-masing stasiun penakar curah hujan dan Jurusan Teknik Sipil Unnes yang telah membantu proses penelitian yang dilakukan.

\section{DAFTAR PUSTAKA}

[1] Mulyanto, H.R. 2018. Pengelolaan Sedimen Terpadu. Yogyakarta: Teknosain.

[2] Mulyana, A. R. dkk. 2012. Optimasi Kapasitas Tampung Baangunan Sabo Pasca Erupsi 2010. Bandung: Puslitbang Sumer Daya Air.

[3] Soemartono, C. D. 1987. Hidrologi Teknik. Surabaya : Usaha Nasional.

[4] Sri Harto Br. 1993. Analisis Hidrologi. Jakarta : Gramedia Pustaka Utama.

[5] Natakusumah, D.K. dkk. 2011. Prosedur Umum Perhitungan Hidrograf Satuan Sintesis Cara ITB dan Beberapa Contoh Penerapannya. Bandung : Jurnal Teknik Sipil-ITB, 253.

[6] Linsley, R. K. 1996. Hidrologi Untuk Insinyur. Jakarta : Erlangga.

[7] Asdak, Chay, 2007. Hidrologi dan Pengelolaan Daerah Aliran Sungai. 
Yogyakarta: Gadjah Mada

University Press.

[8] Badan Standarisasi Nasional. 2016.

Tata Cara Perhitungan Debit Banjir

Rencana. (SNI 2415-2016). Jakarta

Pusat : Badan Standarisasi Nasional

[9] Puslitbang Sumber Daya Air. 2012.

Bangunan Sabo di Indonesia.

Bandung : Puslitbang Sumber Daya

Air.

[10] Sudrajad, Imam. 2020. Dimensi dan

Stabilitas Sand Pocket di Kali Woro,

Koordinat $\quad 7^{\circ} 44^{\prime} 42.3^{\prime \prime} \mathrm{LS}$, 10³1'53.9" BT Klaten, Jawa

Tengah. Semarang : Jurusan Teknik Sipil Fakultas Teknik Universitas

Negeri Semarang.

[11] Badan Standarisasi Nasional. 2015.

Desain Bangunan Penahan

Sedimen. (SNI 2815-2015). Jakarta

Pusat: Badan Standarisasi Nasional.

[12] Departemen Permukiman dan Prasarana Wilayah. 2004.

Perencanaan Teknis Bendung Pengendali Dasar Sungai. (Pd T-122004 A). Jakarta Selatan : Departemen Permukiman dan Prasarana Wilayah. 